\title{
The Development Tendency of Curricula Construction in College Shufen Qiu
}

\author{
Jiangxi Institute of Fashion Technology, Nanchang 330102, China \\ 459120809@qq.com
}

Keywords: college curricula, curricula construction, student orientation, development tendency

\begin{abstract}
It is important that curricula play an important role for the all-round development of students. To reinforce the college curricula construction, which needs to seize the development tendency. From the perspective of the status of curricula in college, curricula construction is coming from the edge to the center; from the perspective of education idea development, curricula construction is changing from teaching orientation to learning orientation; from reform development process and inner logic, curricula construction is turning from curricula development to curricula understanding; from the perspective of teaching method reform,curricula is shifting from closure and unidirection to openness and interaction.
\end{abstract}

\section{Introduction}

Universities around the world are focusing more on sustainability, not only in their academic education but also in the overall administration of their campuses. Sustainability is becoming more important for both students and the employers hiring them upon graduation. [1] As you know, curricula should keep sustainability in universities. Curricula is the basic gist of cultivating and teaching; curricula is fundamental guarantee to achieve the goal of college education, which plays a deceive role for the all-round development of students. Curricula construction was discussed from the perspective of micro and middle level in many documents. Here I'd like do some exploration on curricula construction from the perspective of macro level to draw the discussion from people who are interested in the theme.

\section{From the Edge to the Center}

\subsection{The Reasons of Paying Attention to the Curricula.}

Requirement of the society development. With the development of modern society, internationalization, informatization, urbanization and marketization is coming. More and more high and new requirements towards the talents are required by the modern society. During the education practice, when colleges are meeting the needs which are appearing withe the development of the society, curricula as the breakthrough to meet the social needs and achieve the aim of reforming higher education through the reform of curricula in college, addition of new curricula, the reform of curricula structure and increase of new function.[2]

Requirement of enhancing quality of higher education. From the beginning of 2002, higher education in our country was entering the massive time. Up to the year of 2013, the number of all kinds of students in institutions amounted to 33 million 250 thousand and gross enrollments ratios of higher education achieved 30\%. The task of higher education scale development already achieved and have entered the period of improving quality. The party central committee had clearly made the goal that enhancing the quality of higher education was a strategy task of promoting the development of higher education. It is obvious that the enhancing of higher education quality can not go far without curricula and curricula construction.

Requirement of implementing the establishment of autonomy of higher education. Higher education law reinvests the autonomy of higher education. At the aspect of training person, the 31th Article of it's makes rule that colleges should center the training of talents to develop the teaching, research and social service. Colleges must ensure that the quality of teaching and education meet the 
needs of national regulations; the 33th Article of it's makes rule that colleges could adjust and ste up it's subjects and majors according to the higher education law; the 34th Article of it's makes rule that colleges autonomously draw up a plan of teaching, choose suitable teaching materials and organize teaching actives. Due to the factors of plan market, several years ago, the government controlled much towards colleges, the right of higher education autonomy could not get implement completely. Now, colleges obtain the right of higher education autonomy gradually, and the problems of curricula and curricula construction need to be researched and carried willingly to ensure the quality of teaching.

Therefore, we must enhance the cognition of importance towards curricula construction, which is the premise of strengthening curricula construction.

\section{2 curricula is the combination of students and colleges, students and society, teaching and research.}

Curricula is the combination of students and colleges. Why we need build colleges? The aim is to cultivate the talents. Make high moral values establishment and people cultivation is not only the basic aim of college education, but also the fundamental task of college education. How to finish the task and aim? We must depend on the curricula. Colleges set up a series of curricula according to the requirement of the subject and the major cultivation aim. Students must learn the curricula one by one, achieve the requirement of the curricula, then could obtain the graduation and degree certification. Therefore, the curricula must embody the requirement of cultivation. However, human being is living entity, having ideology, personality and self-inspirit world. Human being as an entirety, owing moral, wisdom, form and beauty, they could not be separated and the moral is the direction, which is the key of human being development. College students not only learn how to become talents, but also learn how to become all-round person, and the later is the base of the former. Therefore, the curricula should embody the requirement towards the students. Now, knowledge economy time is coming, and creation is the essence of knowledge time. Cultivate creation talents is the basic requirement of modern education. So, the curricula must be reformed to achieve the aim of cultivating creation talents. Through the learning in colleges, the students must master the basic knowledge and own the ability, which must realize through the curricula.

Curricula is the combination of students and society. The students lives in the society, and they must work in the society after graduation. The students is close to the society, and the curricula is the combination. First, the requirements of society towards talents embody the subject aim and the subject structure. For example, according to the requirement of society towards the talents, UK putted forward national subject aim: let the young become the successful learners, confident individual, responsible citizens and effective constructions.[3] Second, the society is complex, and all kinds of information combined together, leading to the dilemma of choosing in value for students. Through the selection of curricula, colleges choose education resource to intensify the positive effect and decrease the negative effect to the least, helping the students to grow up healthily. Finally, some practice curricula should be taught to lead students to join in practice and grow up in social practice. Marxism thought that the social actives of human being is practical in essence. Through the practice, the students could know about the society, national conditions; enhance the responsibility of society; exercise willpower and cultivate character; enhance the ability and serve the society. Only through the practice, the idea off liking to study, liking to labor and motherland could be cultivated.

Curricula is the combination of teaching and research. Talents cultivation, science research and social service are the fundamental functions of colleges. As you know, science research in university is not the real purpose for the research fruits, it is more important to cultivate talents. Firstly, research actives should be introduced to the curricula. Teachers and students develop research together, learning in the research. This learning contains the cultivation of science attitude and spirit, the master of research ability, research method and science knowledge. Only join in the practice in person, could he or she know that the process of science research must abide by the strict rules and procedures. Any Phony is not accepted in the science research, otherwise the research fruits could not birth. Only join in the practice in person, he or she know the essence and the regular of the things profoundly. 
Secondly, the research fruits must be introduced into the curricula. Many research actives (such as 863 and 973 project) from teachers may not have direct relation with teaching, but we could achieve the close combination of teaching and research through the introduction of research fruits into the curricula. Some scholar thought that a new curricula could be created if there were about 10 thesis which were excellent in certain aspect.

\section{From Teaching Orientation to Learning Orientation}

From teaching orientation to learning orientation means from teaching center to learning center. Education ideology changes according to the development of the society. Now we are entering information society from industrial society. The National Medium-and Long- Term Plan for Education Reform and Development (2010-2020) had put forward that information technology has revolutionary effect towards the education development, great attention must be paid to it. We must change our ideology radically, student-centered, realizing the change from teaching orientation to learning orientation, which means to change from teachers imparting knowledge to students finding and creating knowledge, change from imparting model to learning model.[8]

We must realize that it is the history requirement to establish students orientation ideology and achieve the change from teaching orientation to learning orientation. Then how to promote the change? Firstly, we must change our education ideology and make all-round design; secondly, the teachers must change the method, the way and the means of teaching; thirdly, enhance the guide to the students learning; fourthly, change the system and adjust adjust the policy.

The students development make us to develop curricula. The aim of curricula construction is to promote the development of students. However, there are continuity and periodicity in one's life development. When we develop new curricula, we must consider the development regular of the students. We develop new curricula to make students could learn knowledge willingly. What's teaching? Teaching should build on the base of original knowledge of learners and lead the learners obtain new knowledge.[10] what's more important, the interaction of teachers and students in new curricula development is necessary. Especially the joining of students curricula, which could rich the contends and forms of teaching in class and explore the depth and width of curricula teaching. In teacher's eye, the students are no longer the passive receiver of knowledge and the actives and positives of students in class are emphasized.

\section{From Curricula Development to Curricula Understanding}

We should pay attention to the curricula understanding when we are enhancing the curricula development. In some colleges of our country, curricula construction is still on the edge and develops slowly, and many problems are waiting for being discussed, such as General Education and specialized education, scholar and application, compulsory courses and selective courses, theory and practice, in class and out of class. Therefore, curricula development must be enhanced.

The goal of curricula, structure, teaching materials and teaching method must be discussed and explored. At the same time, we must pay attention to curricula understanding, and combine curricula understanding and curricula development. Generally speaking, curricula contains overt curricula and hidden curricula. What we usually say are overt curricula.however, in class, the teachers' body language, such as his or her voice, tone, demeanor, temperament, feeling, idea, faith and pursuit are all the contents of culture, which are all hidden curricula. Besides, class culture has close relationship with hidden curricula. Class culture exist really and has deep effect to the students. We can recommend the teaching plan and materials from Harvard University and Oxford University, but could not research the same effect with the Harvard and Oxford University, that's because we have no way to introduce their class culture. Class culture must be created and cultivated and the forms are rich and various. Professor Ye Lan tried to construct a creative class culture with full of living through the form of making a detailed inquiry. What she asked questions towards the teachers are as follows: could you heard the creation from the students answers? Could you feel the subtle progress and 
change from the students? Could you make the students understand the mistake what they made? Could you use different languages to make the students pay attention to you? Could you let the students feel that your spirit pulse are jumping with them? Could you let the debate from the students collide spark new ideas?could you make the students cooperate in class and feel comfortable and find surprise?[16]

\section{Summary}

Curricula construction plays an important role in strengthening the country through talents. There is no doubt that curricula needs theory guide. We could mirror the curricula theory from Europe and American. However, if we depend on it totally to guide curricula practice, the problem in curricula construction could not be solved completely, even get half the results with twice the effort. We must depend on the Chinese traditional culture to build our curricula construction theory. Happily, the exploration had already started and made great progress. Professor Zhang Chuting put forward five Is ( information over knowledge; interest before stamina; intuition above logic; inquiry beyond listening; intelligence )in his curricula research from the philosophy of education height. [17]We expect more and more exploration towards curricula construction to appear.

\section{References}

[1]. Bilge Gokhan Celik, Mehmet E. Ozbek, Sharmin Attaran, Maral Jalili . Comparison of Environmental Responsibility of Construction Management Students Based on Exposure to Sustainability in Curricula and on Campus. International Journal of Construction Education and Research, Vol.10 (2), 2014, pp.96-110.

[2]. Guo Dejiang, the Historical Evolution of University Curricula Idea in America[M]. Beijing, Central Edition and Translation Publishing House,2007:2.

[3]. John White, What Schools Are for and Why? Higher Education Research. Translation by Zhao Xiantong , Yang Xingfang. 2013,(12): 11.

[4]. Barr Tagg. From Teaching to Learning--A New Paradigm for Undergraduate Education[J]. Change. 1995.(11/12):13-15.

[5]. Liu Xianjun. Seize Four Key Questions to Enhance University Graduate Curricula Construction[J]. China Higher Education, 2013, (17) :40-43.

[6]. Ye Lan. Let Class Spark Living[J]. Education Research. 1997.(9): 3-8.

[7]. Zhang Chuting. Curricula and Education Philosophy[M]. Beijing: People Education Publishing House, 2003: 135-151. 